\title{
O ENEM no contexto das políticas para o Ensino Médio
}

\author{
Paulo Henrique Alves Machado*
}

Elizeth Gonzaga dos Santos Lima**

\section{Resumo}

Este artigo tem como objetivo compreender os determinantes do Exame Nacional do Ensino Médio (ENEM), analisando a política de reforma do Ensino Médio e suas interfaces com a avaliação representada pelo exame, no contexto da promulgação da Lei de Diretrizes e Base no 9.394/96 até o novo ENEM em 2009. A metodologia utilizada partiu de uma abordagem qualitativa, tendo como procedimento a análise de conteúdo dos documentos, sistematizada através de três categorias (avaliação, trabalho e cidadania), cuja empiria constitui-se dos documentos: Parecer CEB no 15/98, Resoluçáo CNE no 03/98, Bases legais dos PCNEM, além das portarias no 438/98 e no 109/2009. As análises dos documentos que sustentam a reforma do ensino médio mostraram que o ENEM é coerente com a política para essa etapa da Educação Básica, uma vez que seus princípios podem ser identificados tanto na Lei de Diretrizes e Base quanto nos demais documentos analisados. Os resultados da pesquisa também indicaram que os princípios valorizados pelos organismos multilaterais, nos anos de 1990, estão presentes na reforma do ensino médio e tem relação direta com a política neoliberal.

Palavras-chave: Ensino Médio. Avaliação. Exame Nacional do Ensino Médio.

\footnotetext{
* Graduado em Letras - Português e Inglês pela Universidade Federal do Mato Grosso do Sul (UFMS). Mestrando em Educação na Universidade do Estado de Mato Grosso (UNEMAT). Professor da Secretaria de Estado de Educação de Mato Grosso.

** Doutora pela Universidade Estadual de Campinas (UNICAMP). Professora do Programa de Pós-Graduação em Educação e do Curso de Pedagogia da Universidade do Estado de Mato Grosso (UNEMAT).
} 


\section{Introdução}

O presente artigo resulta do esforço em compreender de que maneira o Exame Nacional do Ensino Médio (ENEM) situa-se dentro da política de reforma do Ensino Médio (EM), iniciada a partir da Lei de Diretrizes e Bases (LDB), n. 9.394/96 (BRASIL, 1996), para que se possa compreender o papel dessa etapa da educação básica na contemporaneidade e quais relaçôes e determinaçôes existem entre a política do EM e a política de avaliação do ENEM.

Para tanto, a despeito dos determinantes da avaliação do Ensino Médio, emergem alguns questionamentos, que constituem a problemática deste estudo: a avaliação do ENEM, sistematizada nos documentos que a estruturam está sustentada na política do Ensino Médio? A política de reforma do EM, desenhada a partir da LDB 9394/96, de fato sustenta a avaliação do ENEM? Então quais determinantes da política que sustenta o ENEM podem ser identificados a partir dos documentos investigados?

Essa pesquisa teve, portanto, como objetivo geral, compreender os determinantes do ENEM, analisando a política de reforma do EM e suas interfaces com a avaliação representada pelo exame, no contexto que vai da promulgação da LDB 9.394/96 até o Novo ENEM em 2009.

\section{Princípios metodológicos}

Em vista disso, foi pertinente optar por uma abordagem teóricometodológica de natureza qualitativa, na qual os documentos estruturais da política de educação para o Ensino Médio, bem como as portarias que sustentam o ENEM constituíram a base empírica do trabalho. Dessa forma, a técnica da Análise de Conteúdo, sustentada nos estudos de Bardin (2009) e centrada no estudo de categorias, ofereceu uma alternativa viável como procedimentos para análise dos dados coletados, uma vez que busca a compreensão das relações que podem revelar muito mais do que aquilo que está escrito.

A linguística estabelece o manual do jogo da língua; a análise de conteúdo tenta compreender os jogadores ou o ambiente do jogo num momento determinado, com o contributo das partes observáveis. Contrariamente à lingüística, que apenas se ocupa das formas e da sua 
distribuição, a análise de conteúdo toma em consideração as significações (conteúdo), eventualmente a sua forma e a distribuição destes conteúdos e formas (índices formais e análise de co-ocorrência). (BARDIN, 2009, p. 45).

Coerente, portanto, com o método de Análise de Conteúdo, a organização da análise documental consistiu na pré-análise dos documentos, a exploração do material (identificaçâo das categorias), além do estabelecimento de quadros de resultados, oferecendo uma condensação das informaçóes fornecidas pela análise.

Antes, porém, da realização de tais etapas, fez-se necessário situar esta pesquisa dentro do universo das discussóes pertinentes aos temas avaliação e política do EM. Dessa maneira, realizamos um balanço da produção científica, que antecedeu as etapas de levantamento e análise. Esse balanço consistiu no levantamento da produçáo acadêmica sobre o assunto (entre os anos 2000 e 2009), conforme Bergmann (2009), através dos resumos existentes no Banco de Teses da Capes para situar em que nível se encontrava a discussão sobre a política do EM, bem como sobre o ENEM.

Como bases empíricas deste trabalho, para coleta das informações, foram selecionados documentos referentes à reforma do EM, no período pós LDB, que sustentam as análises empreendidas:

- Lei no 9.394 de 20/12/96 (LDB) (BRASIL, 1996);

- Parecer da Câmara de Educação Básica no 15/98 (BRASIL, 1998b);

- Resolução do Conselho de Nacional de Educação nº 03/98 (BRASIL, 1998c);

- Documento "O novo Ensino Médio", contido nas Bases Legais dos Parâmetros Curriculares Nacionais para o Ensino Médio (BRASIL, 2000);

- Portaria Ministerial no 438, de 28 de maio de 1998 (BRASIL, 1998a);

- Portaria Ministerial no 109, de 27 de maio de 2009 (BRASIL, 2009).

Para auxiliar na reflexão inicial, entendemos que, ao buscar compreender as interfaces entre o ENEM e o conjunto da política de reforma do EM, era importante investigar a categoria avaliação, definida a priori. No entanto, ao longo da leitura dos documentos, surgiram as categorias trabalho e cidadania, que permearam todos os documentos, despertando interesse pela frequência desses 
indicadores, que apontavam para a existência de duas categorias importantes para a compreensão da política do EM, como contextos fundamentais para a educaçáo.

Gostaríamos de esclarecer, em tempo, que, apesar do recorte histórico da pesquisa abranger os documentos da Reforma do Ensino Médio, com a promulgação da LDB no 9394/96 até o Novo ENEM em 2009, para compreender a construção histórica do Ensino Médio no Brasil, fez-se necessário, no primeiro momento do trabalho, compreender esse processo histórico a partir da década de 1930, bem como seus desdobramentos até o final do século XX, momento no qual ocorrem os primeiros, e fundamentais, passos para a política de reforma do EM.

\section{A reconfiguração do Estado e o surgimento da avaliação}

De acordo com os levantamentos históricos, o Estado, no início da década de 1930, configura-se como conservador, mas tolerante às propostas dos liberais para a educação; depois, autoritário e antiliberal, conforme indica a Constituição de 1937. Já a Constituição de 1946 confere características liberais ao Estado e, após o golpe se 64, mesclam-se o autoritarismo com uma política econômica de perfil liberal, até dar lugar ao neoliberalismo.

Já no século XX o papel do Estado foi sendo revisto com o desenvolvimento do capitalismo e a organização da classe trabalhadora contestando sua náo participação nas vantagens do desenvolvimento produtivo, com a necessidade de manutenção da reprodução das forças produtivas e as dificuldades enfrentadas pelo próprio mercado. Dentro do pensamento liberal foram ganhando espaço as questóes sociais, e o Estado cumprindo um papel que lhe era conferido, de mediador passou a gestor (GENTIL, 2003, p. 45).

A constatação de que entre o desenvolvimento econômico e as forças culturais do país não havia uma articulação que favoreceria o desenvolvimento do sistema, anunciada pelos Pioneiros da Educação Nova na década de 1930, persistiu como uma característica ao longo de todo o século XX.

A luta, portanto, entre os defensores do conservadorismo e do liberalismo representou um entrave para o avanço do capitalismo e da educaçáo necessária 
para a modernização do mercado no país. A partir da década de 1970, o enquadramento da educação nos moldes de um capitalismo que também se reestruturava era ainda mais urgente para o Brasil, no entanto, os avanços na área eram ainda modestos. Desta forma, o Estado buscará afinar-se com o patamar de desenvolvimento do capitalismo fora das fronteiras do país.

O contexto histórico nos mostra que o EM, desde sua origem, carrega o dilema que se situa entre a educação em caráter de terminalidade para o mundo do trabalho e a educação preparatória para o prosseguimento dos estudos na educação superior (propedêutico). Dilema esse que vai acirrando ainda mais ao longo das décadas do século XX, culminando, na década de 1990, com as propostas de organismos internacionais para a educação do século XXI e a implantação das políticas de avaliação, determinando um contexto de reforma da educação, visando a conformação com princípios neoliberais.

O capitalismo, ao longo de sua construção histórica, apresenta períodos de intenso desenvolvimento, alternando crises decorrentes das contradiçóes do próprio sistema. Segundo esclarece Dalagasperina (2006), a década de 1970 foi marcada por uma dessas crises, levando a maioria dos países capitalistas a vivenciarem uma crise estrutural, provocada por alteraçóes nos campos político, econômico e social. Porém, no bojo dessa crise, surgiu uma alternativa para redimensionar as formas de produção e relações sociais, o que ocasionou a reformulação das estratégias capitalistas. Diante da necessidade de reverter a crise econômica mundial, os princípios liberais são reafirmados, ganhando novos elementos, resultando no modelo econômico neoliberal, que busca reordenar a esfera produtiva com relação à produção, ao consumo de mercadorias e aos serviços, além de limitar as intervençôes do Estado.

A ideologia mais veiculada pelo neoliberalismo é a que não há nenhuma outra saída para o mundo a não ser ajustarse ao processo de globalização. Esse ajuste se daria pela desregulamentação, um Estado mínimo, um mínimo de direitos garantidos aos trabalhadores, o mercado regulando todas as relaçôes sociais. (GENTIL, 2003, p. 47).

Conforme esclarece Peroni (2007), o Estado mínimo proposto é mínimo apenas para as políticas sociais, em contrapartida, é máximo no sentido de regular as atividades do capital corporativo, além de estar entre suas atribuiçôes a prerrogativa de criar condiçôes atrativas para o capital. 
Os países capitalistas mobilizam-se, portanto, a partir da década de 1970, para restabelecer o desenvolvimento econômico, visando reformular a política econômica mundial e superar as orientaçôes keynesianas, adotando uma postura voltada aos princípios fundamentais do liberalismo: a livre concorrência e a mínima intervenção do Estado. Essa reconfiguração do Estado, a partir das últimas décadas do século XX no Brasil, terá entre suas principais prerrogativas a função de avaliar os serviços oferecidos pelas instituiçôes a ele ligadas. De acordo com Lima (2008), o Estado de bem estar social, desenvolvido na Europa a partir da II Guerra Mundial, trouxe consequências estruturais para o capitalismo, ocasionando acumulaçáo desordenada e desigual do capital, desemprego estrutural, com empregadores exercendo maior pressão sobre a força de trabalho.

A partir dos anos de 1990, busca-se alcançar equidade, qualidade e eficiência na educação brasileira, sob influência da Conferência de Jomtien (1990), bem como do documento da Comisión Económica para América Latina y el Caribe (CEPAL) Transformación productiva con equidad, recomendando que:

[...] os países da região investissem em reformas dos sistemas educativos para adequá-los a ofertar os conhecimentos e habilidades específicas requeridas pelo sistema produtivo. Eram elas: versatilidade, capacidade de inovação, comunicação, motivação, destrezas básicas, flexibilidade para adaptar-se a novas tarefas e habilidades como cálculo, ordenamento de propriedades e clareza na exposiçáo, que deveriam ser construídas na educação básica. (SHIROMA; MORAES; EVANGELISTA, 2007, p. 53).

Em 1992, dois anos mais tarde, a CEPAL produziu o documento intitulado Educación y conocimiento: eje de la transformación productiva con equidad em parceria com a UNESCO, onde apresentava diretrizes para políticas que favorecessem a educaçáo, o conhecimento e o desenvolvimento nos países da América Latina e Caribe. Esse documento destaca a necessidade de reformas administrativas que possam reformular o papel do Estado, que passaria de administrador e provedor à Estado avaliador.

Dessa forma, esforços e investimentos foram mobilizados para a elaboração de um complexo de regulação, que tinha por meio a avaliação, para promover a reforma na gestão da educação básica. O que se justifica por uma 
nova configuração do Estado, "Especialmente as iniciativas do estado central no período de 1995-2002 indicaram como ganhou forma objetiva, no Brasil, um modelo de Estado-regulador e Estado-avaliador que supôs o enfranquecimento do Estado-executor" (FREITAS, 2007, p. 119). A regulação da educação básica pelo Estado, entretanto, torna-se nítida e consistente dentro do aparato normativo, a partir de 1996.

Os efeitos da crise internacional, no Brasil, causada pela decadência do modelo de Estado de bem estar social, foram as altas taxas de juros combinadas com elevadas taxas de inflação que levaram ao crescimento da dívida externa (LIMA, 2008). Dentro desse contexto, o governo Fernando Henrique Cardoso, em 1995, propóe uma reforma do Estado Brasileiro (PERONI, 2003). Para tanto, cria o Ministério da Administração e Reforma do Estado (Mare), que apresentou o Plano Diretor da Reforma do Aparelho de Estado em novembro de 1995.

O objetivo da reforma "[...] era reforçar a capacidade de governabilidade do Estado" (PERONI, 2003, p. 59), deixando de lado a rigidez burocrática e ineficiência, para dar lugar a "[...] uma administração pública gerencial, flexível e eficiente, voltada para o atendimento da cidadania" (BRASIL, 1995, p. 13).

É importante destacar que o Plano Diretor da Reforma se refere à educação como essencial para o desenvolvimento, já que envolve investimento em capital humano. A avaliação, portanto, aparece no documento como parte de uma administração pública gerencial, cujos critérios são "[...] a admissão segundo rígidos critérios de mérito, a existência de um sistema estruturado e universal de remuneração, as carreiras, a avaliação constante de desempenho, o treinamento sistemático" (BRASIL, 1995, p. 16).

$\mathrm{Na}$ verdade, essa avaliação exigida pela reforma do Estado em 1995 era um reflexo das recomendaçóes das agências multilaterais para os países em desenvolvimento: "[...] desde o governo de Fernando Collor de Mello a agenda de reforma administrativa passou a refletir a agenda internacional de reforma do Estado difundida pelas agências multilaterais" (FREITAS, 2007, p. 71). Dalben (2003) refere-se especificamente ao Banco Mundial que vincula às suas linhas de crédito à necessidade de indicadores que possam sinalizar a melhoria na qualidade da educação.

A materialização da avaliaçẫo na reconfiguração do Estado encontra-se no artigo 9, parágrafo VI, da LDB 9394/96, que diz ser incumbência da Uniáo (ou seja, do Estado) "[...] assegurar processo nacional de avaliaçấo do 
rendimento escolar no ensino fundamental, médio e superior, em colaboração com os sistemas de ensino, objetivando a definiçâo de prioridades e a melhoria da qualidade do ensino" (BRASIL, 1996).

É nesse contexto que surge o Exame Nacional do Ensino Médio (ENEM), criado em 1998 pelo Instituto Nacional de Estudos e Pesquisas Educacionais Anísio Teixeira (Inep), do Ministério da Educação. Ao longo da primeira década do século XXI, foi utilizado como instrumento de certificação de conclusão do Ensino Médio, bem como de critério de acesso ao ensino superior, através de programas como Programa Universidade para Todos (ProUni) e Fundo de Financiamento Estudantil (FIES), além de ter sido aceito como exame de seleçâo para a maioria das universidades federais do Brasil.

O ENEM é uma avaliação constituída a partir de uma matriz de habilidades e competências que sintetizam os conteúdos ministrados no ensino fundamental e médio. Suas médias, obtidas por escola, podem ser observadas na Internet num ranking de escolas de acordo com as médias obtidas através do cálculo da nota dos candidatos. Sousa (2011) afirma que o ENEM não pode ser considerado um exame que avalia o EM, pois, embora venha sendo difundido como exame para essa etapa do ensino, seus resultados não evidenciam a qualidade do EM, cujos objetivos (tanto na sua versão antiga quanto a nova) refletem "[...] o propósito de avaliar individualmente alunos concluintes e egressos do ensino médio quanto às competências especialmente definida para esse exame" (SOUSA, 2011, p. 102).

Conforme fica evidenciado através dos levantamentos efetuados nesta pesquisa, a emergência de um Estado de perfil neoliberal, durante a década de 1990, reforça a necessidade da avaliação no contexto educacional, como forma de aferir os resultados para efetuar as medidas necessárias em busca da oferta de melhores serviços. Dessa forma, a política de reforma do Estado brasileiro materializa a avaliação através da LDB e posteriormente com a criação do ENEM. Entretanto, o exame não avalia tecnicamente o EM, mas apenas os concluintes dessa etapa da educação básica.

A definição de avaliação, conforme esclarece Lima (2008, p. 8), está condicionada a nossa concepção de sociedade e de educaçáo e, dessa forma, constitui "[...] um caminho que deve ser construído pelos sujeitos a partir das relaçooes interpessoais estabelecidas na coletividade". O que leva a concluir que o ato de avaliar é próprio da natureza humana, ou melhor dizendo, é natural às necessidades históricas do ser humano. 
Esta interação entre os homens levou às mudanças e transformaçóes políticas, culturais, sociais e econômicas. As açóes de criticar, analisar, verificar, classificar, medir, selecionar e buscar melhorias é um processo inerente ao ser humano. Dessa forma, podemos dizer que avaliar não é um processo novo, tampouco está distante do homem; é uma ação oriunda das relaçóes sociais e interpessoais como uma necessidade natural de construção e reconstruçáo, denominada no campo da avaliação como informal. (LIMA, 2008, p. 8).

Com a ascensão do paradigma neoliberal, o Estado passa a exercer, portanto, um forte controle e fiscalizaçáo sobre os serviços públicos, utilizando a avaliação com o duplo propósito de analisar a eficiência dos programas para poder melhorá-los para a sociedade, além de, por outro lado, justificar cortes de financiamento e "rebaixamento da fé pública" (DIAS SOBRINHO, 2002, p. 28). Nesse contexto, era preciso também mudar as formas tradicionais de avaliação aplicadas pelas administraçóes centrais, bem como pela escola, pois a sociedade revelava problemas tão complexos que não poderiam ser resolvidos com a exatidão na qual acreditavam os positivistas.

Os governos de máos dadas com o mercado exigiam agora maior eficiência na produçáo das qualidades e dos perfis requeridos nesta nova fase do capitalismo, as famosas competências e habilidades, em substituição dos princípios democráticos e pluralistas dos anos anteriores, que lutavam pelas idéias de igualdade e acesso à educação. A avaliação assumiu basicamente as características de accountability: uma forma tecnocrática de valorar e um procedimento burocrático de exigir o cumprimento das obrigaçôes (DIAS SOBRINHO, 2002, p. 29, grifo do autor).

Surge assim o caráter gerencial da avaliação, que se torna um importante instrumento dentro dessa concepção de administração. Segundo Dias Sobrinho (2002, p. 29), os exames nacionais - que nos interessa particularmente - com a finalidade de revisar a base nacional da educaçáo servem como um diagnóstico para os clientes e para o governo: "[...] uma ferramenta para informar e legitimar as medidas impopulares que os governos tiveram que tomar e que 
freqüentemente significam cortes de orçamento”.

\section{O ENEM no contexto das Políticas para o Ensino Médio: o que os documentos oficiais revelam}

$\mathrm{Na}$ apresentação do documento Exame Nacional do Ensino Médio (Enem): fundamentação teórico-metodológica (BRASIL, 2005), o Diretor de Avaliação de Certificação de Competência do Inep, Ataíde Alves, faz uma declaração que pode dar uma pista quanto às reais pretensôes do exame:

O Enem tem, ainda, papel fundamental na implementação da Reforma do Ensino Médio, ao apresentar, nos itens da prova, os conceitos de situaçãoproblema, interdisciplinaridade e contextualização, que são, ainda, mal compreendidos e pouco habituais na comunidade escolar. A prova do Enem, ao entrar na escola, possibilita a discussáo entre professores e alunos dessa nova concepção de ensino preconizada pela LDB, pelos Parâmetros Curriculares Nacionais e pela Reforma do Ensino Médio, norteadores da concepção do exame. (BRASIL, 2005, p. 8).

Conforme esclarece Ataíde Alves, portanto, o ENEM pretende provocar transformaçóes na educação brasileira, não apenas através de políticas centrais, no nível dos sistemas de ensino, mas provocar discussóes sobre a qualidade da educação no interior das próprias escolas, entre educadores e alunos, repensando não só os currículos, mas também a metodologia aplicada em relação àquela preconizada pela reforma do EM (BRASIL, 2005).

No Parecer no 15/98 (BRASIL, 1998b), que trata das diretrizes curriculares para o EM, o trabalho e a cidadania sáo mencionados como os principais contextos nos quais a capacidade de aprender (e continuar aprendendo) deve ser aplicada, para que o educando possa se adaptar às condiçóes em mudança na sociedade. Essa referência do parecer, bem como a frequência das palavraschave (que permearam toda a empiria analisada), tornaram-se fundamentais para escolher o trabalho e a cidadania como categorias para a análise desta pesquisa, por entender que esses índices têm o potencial necessário para explicar as interfaces entre política do EM e a avaliação do ENEM. 
Resta saber, agora, qual cidadania e qual trabalho são esses dos quais os documentos tanto fazem referência? A Constituição federal de 1988 já se referia aos termos no seu art. 205: "A educação, direito de todos e dever do Estado e da família, será promovida e incentivada com a colaboraçấo da sociedade, visando ao pleno desenvolvimento da pessoa, seu preparo para o exercício da cidadania e sua qualificação para o trabalho" (BRASIL, 1988). Como se vê, o preparo para o exercício da cidadania e a qualificação para o trabalho são pilares que sustentam a educação preconizada na Constituição federal.

A formação geral para o trabalho, de acordo com os documentos examinados, refere-se à concepçáo burguesa e alienada do termo trabalho que, por sua vez, está ligada a atuação no mercado. Dessa forma, o trabalho figura como um elemento essencial para a reprodução do sistema capitalista. Apesar disso, encontra-se uma contradição no Parecer no 15/98 (conforme referência feita na página 107), já que o trabalho se revela também como uma necessidade humana permanente (BRASIL, 1998b). O que demonstra que o pensamento em torno da concepção de trabalho não é tão fechado, apontando para uma alternativa na abordagem do trabalho.

A frequência da categoria cidadania é bastante inferior à categoria trabalho (cidadania -66 vezes e trabalho -182 vezes). No entanto, em muitos momentos na empiria, as duas palavras aparecem associadas. Portanto, faz-se necessário compreender que sentido, ou sentidos, pode ter o termo dentro de nossa sociedade. Segundo Rezende Filho (2001), apesar da dificuldade em precisar no tempo o surgimento do termo cidadania, sabe-se que o mesmo está ligado ao desenvolvimento das poleis gregas, entre os séculos VIII e VII a.C. Período em que, a propósito, a palavra tinha o sentido de naturalidade, ou seja, cidadão grego era aquele nascido em terras gregas; no entanto, com o passar do tempo e a abolição da escravidão entre eles, os estrangeiros passaram a ser aceitos entre os cidadãos. De qualquer forma, o termo manteve seu sentido, ao longo do tempo, de participação política.

$\mathrm{Na}$ busca de um conceito de cidadania a partir dos documentos analisados, podemos dizer que o termo tem relaçáo com a vida em sociedade e, por conseguinte, com os direitos e deveres. No entanto, apesar de haver uma dicotomia, identificada na totalidade dos documentos analisados, entre trabalho e cidadania, observamos que essas duas categorias convergem em um único sentido. Essa convergência materializa-se no art. $1^{\circ}$ da Portaria 109/2009 - Portaria do Novo ENEM (BRASIL, 2009). Por outro lado, o 
Parecer declara, ainda, que a cidadania tem a propriedade de manter a unidade do tecido social.

De acordo com os estudos realizados, a avaliação, no contexto neoliberal, tem servido tanto para analisar a eficiência dos programas de ensino quanto para justificar cortes de verbas para a educação. De modo geral, uma avaliação diagnóstica deve ter como objetivo maior identificar deficiências para reconstruir as práticas em busca de melhorias. Mas o que o ENEM pretende, portanto, avaliar? $\mathrm{O}$ exame busca avaliar as habilidades e competências necessárias para o trabalho no mundo produtivo e ao exercício da cidadania.

O trabalho e a cidadania são dois contextos fundamentais na doutrina que rege o currículo no EM e que devem ser utilizados na transposição didática do conhecimento, contextualizando-o, lançando mão, em muitos momentos, do trabalho interdisciplinar para tanto. Trabalho e cidadania aparecem, na maioria das vezes, associados como se fossem elementos indissociáveis, ou complementares, chegando mesmo a convergirem, conforme se encontra na Portaria no 109/2009 (BRASIL, 2009).

O princípio do trabalho pode ser compreendido, de acordo com o levantamento teórico desta pesquisa, como emprego, função assalariada e também como um elemento que define o modo de existência humano. $\mathrm{O}$ EM tem como objetivo também a formação geral para o trabalho, além da possibilidade de conferir habilitaçôes profissionais que dependerão das condiçôes de implantação de cada escola; esse objetivo do EM o coloca em contato como o mundo produtivo (emprego), de forma que o conceito de trabalho ligado ao mercado (emprego) não pode ser ignorado. Por outro lado, o caráter de formação geral para o trabalho - portanto, não específico, mas omnilateral - remete a indicadores que emergem dos documentos analisados (Parecer $n^{\circ} 15 / 98$ e Portaria $n^{\circ} 109 / 2009$ ), relacionando o ser humano ao trabalho, na perspectiva de que o trabalho é essencial para a vida e realização da pessoa. A LDB, entretanto, traça um perfil de egresso do EM e no inciso I, do parágrafo $1^{\circ}$, do art. 36 , e apresenta uma característica ligada à preparação básica para o trabalho: "[...] domínio dos princípios científicos e tecnológicos que presidem a produção moderna” (BRASIL, 1996). Assim, a formação básica para o trabalho consiste no preparo para dominar os princípios científicos e tecnológicos necessários à produção moderna.

A despeito da palavra cidadania, seu sentido liga-se ao conceito de cidadáo, ou seja, aquele que, dentro de um estado de direito, tem seus direitos e deveres. 
Além disso, há uma perspectiva marxista, na qual a cidadania é constituída pela luta da classe trabalhadora em defesa de seus direitos. Os documentos analisados são unânimes ao reconhecer que o exercício da cidadania requer preparo desenvolvido ao longo da educaçáo escolar. Entretanto, o que se esconde sobre a máscara da cidadania pode ser, na verdade, apenas o controle e a manutenção da estrutura social. Em uma sociedade moderna e laica, a cidadania pode desempenhar o papel de elemento aglutinador da sociedade, evitando o esfacelamento social.

O Parecer CEB no 15/98 (BRASIL, 1998b) sugere que trabalho e cidadania convergem de tal forma que as competências e habilidades requeridas para um, são semelhantes às competências e habilidades necessárias para a outra. Finalmente, a Portaria no 109 , que institui o Novo ENEM, declara, em seu artigo $1^{\circ}$, que o exame avalia as competências e habilidades necessárias para o exercício da cidadania, sendo que o trabalho é que passa a se inserir nesse contexto (BRASIL, 2009).

\section{Considerações Finais}

Os dados evidenciados nesta pesquisa nos levaram a buscar algumas respostas para os questionamentos que nos motivaram a empreender este estudo: a avaliação do ENEM, sistematizada nos documentos que a estruturam, está sustentada na política do Ensino Médio? A política de reforma do EM, desenhada a partir da LDB 9394/96, de fato sustenta a avaliação do ENEM?

Essa forma de avaliação proposta pelo ENEM atende ao inciso VI, do art. 9o, da LDB (BRASIL, 1996), que por sua vez, consistia numa exigência de organismos multilaterais que reclamavam por instrumentos de controle dos resultados da educaçáo brasileira sustentados na avaliaçáo do rendimento escolar nos níveis fundamental, médio e superior. O Parecer CEB no 15/98 (BRASIL, 1998b) afirma que exames como o ENEM constituíam importantes mecanismos para promover a eficiência e a igualdade do ensino no país. Essa afirmação foi incorporada pelos Parâmetros Curriculares Nacionais para o Ensino Médio (PCNEM) de 1999 (BRASIL, 2000). Portanto, a avaliação proposta pelo ENEM e a política de reforma do EM se sustentam mutuamente.

Dando continuidade as análises sobre o ENEM, uma terceira dúvida lançava-se em relação aos determinantes desse exame: quais determinantes da 
política que sustenta o ENEM podem ser identificados a partir dos documentos investigados?

No parágrafo $1^{\circ}$, do art. 87 , da LDB, há uma referência clara à Declaração Mundial sobre Educação para Todos, documento elaborado a partir da Conferência Mundial de Educação para Todos (Conferência de Jomtien - Tailândia), conforme se pode constatar: "A União, no prazo de um ano a partir da publicação desta Lei, encaminhará, ao Congresso Nacional, o Plano Nacional de Educação, com diretrizes e metas para os dez anos seguintes, em sintonia com a Declaração Mundial sobre Educação para Todos" (BRASIL, 1996). Apesar de breve, esse parágrafo direciona toda a construção de uma política de reforma do ensino. Fato que pode ser constatado no contexto de todos os documentos que foram analisados, expressando os princípios valorizados pela conferência que, por sua vez, refletem as opinióes dos organismos multilaterais, como, por exemplo, o Banco Mundial nela presente. Aliás, quanto ao Banco Mundial, é importante lembrar que a avaliação era uma de suas exigências para poder acompanhar os resultados obtidos pela educação, que constituía sua principal arma na luta contra o avanço da miséria mundial.

Como náo poderia deixar de ser, o banco, como agência financiadora, estabelece as linhas gerais relativas àquilo que financia e, assim, recomenda sobre a necessidade da eficiência produtiva e relação com o mercado, a gratuidade da escolarização básica, a semiprivatização do Ensino Superior público e, até mesmo, os subsídios relativos ao programa Bolsa Escola para as crianças carentes. (DALBEN, 2003, p. 101).

Nota-se, portanto, que, dentre os organismos multilaterais, o Banco Mundial (enquanto agência financiadora) exerce importante pressão sobre a educaçáo brasileira que, por sua vez, é incumbida de efetivar essa melhor aproximaçáo entre a escola e o mercado. Dessa forma, o ENEM constitui um banco de dados disponível, mediante a autorizaçáo expressa do examinado, para a seleçáo do acesso à educaçáo superior que qualificará essa mão de obra, assim como para a seleçáo imediata, junto aos postos de trabalho. Indispensável dizer que o ENEM tem o controle da mercadoria mais cara ao capitalismo: o trabalhador.

Nessa perspectiva, como é possível situar a cidadania? A reforma do EM aponta para uma cidadania ligada à vida em sociedade, que requer conhecimentos 
básicos que implicam no seu pleno exercício. Tais conhecimentos, ou habilidades e competências, correspondem, basicamente, àquelas necessárias também ao mundo do trabalho, ocasionando uma convergência entre trabalho e cidadania que são os dois principais contextos dentro dos quais a educação deve se dar. Coerente com esse princípio, a Portaria no 109/2009 (BRASIL, 2009) do ENEM enfatiza que seus objetos de avaliação são as competências e habilidade necessárias ao exercício da cidadania, indicando, assim, que o cidadão e o trabalhador equalizam seus papéis em um mundo dominado pelo mercado.

\section{REFERÊNCIAS}

BARDIN, Laurence. Análise de conteúdo. Lisboa: Edições 70, 2009.

BERGMANN, Luana. Para se aproximar da realidade: um balanço da produção científica brasileira sobre a relação entre o público e o privado na Educação, com foco no Instituto Ayrton Senna. Florianópolis, 2009. 24 p. Texto digitado

BRASIL. Constituição da República Federativa do Brasil. Brasília, DF, 5 out. 1988. Disponível em <http://www.planalto.gov.br/ccivil_03/constituicao/ ConstituicaoCompilado.htm>. Acesso em: 5 fev. 2011 Plano diretor da reforma do aparelho do Estado. Brasília: Câmara da Reforma do Estado, nov. 1995. Disponível em: <www.planalto.gov.br/ publi_04/coleção/plondi.htm>. Acesso em: 4 out. 2011.

BRASIL. Lei no 9.394, de 20 de dezembro de 1996. Estabelece as diretrizes e bases da educação nacional. Diário Oficial da Uniāo, Brasília, DF, 23 dez. 1996. Disponível em <http://www.planalto.gov.br/ccivil_03/Leis/L9394. $\mathrm{htm}>$. Acesso em: 12 maio 2010.

BRASIL. Ministério da Educação e do Desporto. Portaria Ministerial n. ${ }^{\circ}$ 438, de 28 de maio de 1998. Institui o Exame Nacional do Ensino Médio - ENEM. Diário Oficial da União, Brasília, DF, $1^{\circ}$ jun. 1998a. Disponível em: <http://www.crmariocovas.sp.gov.br/pdf/diretrizes_p0178-0181_c.pdf >. Acesso em:13 nov. 2010. 
BRASIL. Ministério da Educação. Conselho Nacional de Educação. Parecer $n^{\circ} 15$, de $1^{\circ}$ de junho de 1998, Diretrizes Curriculares Nacionais para o Ensino Médio. Diário Oficial da União, 26 jun. 1998. Disponível em: <http://portalsme.prefeitura.sp.gov.br/Documentos/BibliPed/ TextosLegais/LegislacaoEducacional/Parecer_CNB_CEB_15_98_ InstituiDiretrizesCurricularesNacionaisEnsinoMedio.pdf >. Acesso em: 6 ago. 2010 .

. Resolução CEB/CNE no 03, de 26 de junho de 1998. Institui as Diretrizes Curriculares Nacionais para o Ensino Médio. Diário Oficial da União, Brasília, DF, 5 ago. 1998c. Disponível em: <http://portal.mec.gov.br/ cne/arquivos/pdf/rceb03_98.pdf>. Acesso em: 22 nov. 2010.

Ministério da Educação. Instituto Nacional de Estudos e Pesquisas Educacionais. Exame Nacional do Ensino Médio (ENEM): fundamentação teórico-metodológica. Brasília: MEC/INEP, 2005. Disponível em: <http:// www.acervo.epsjv.fiocruz.br/beb/textocompleto/002985>. Acesso em: 23 mar. 2010.

Instituto Nacional de Estudos e Pesquisas Educacionais Anísio Teixeira. Portaria no 109, de 27 de maio de 2009. Dispóe sobre alteraçóes no Exame Nacional do Ensino Médio. Diário Oficial da União, Brasília, DF, 28 mai. 2009. Disponível em <http://download.inep.gov.br/educacao_basica/ enem/legislacao/2009/portaria_enem_2009_1.pdf>. Acesso em: 26 abr. 2011.

- Ministério da Educação. Secretaria de Educação Média e Tecnológica. Parâmetros curriculares nacionais: ensino médio. Brasília: MEC/SEMTEC, 2000. Disponível em: <http://portal.mec.gov.br/seb/arquivos/pdf/blegais.pdf . Acesso em: 2 abr. 2011.

DALAGASPERINA, Eliana Cristina. A reforma do Estado e as politicas sociais públicas : as perspectivas neoliberais para a política educacional. 2006. $126 \mathrm{f}$. Dissertação (Mestrado em Educação) - Universidade de Passo Fundo, Passo Fundo, RS, 2006.

DALBEN, Ângela Imaculada L. de Freitas. Das avaliações exigidas às avaliaçóes necessárias. In: LISITA, Verbena Moreira S. de S.; FREIRE, Luciana (Org.). Politicas educacionais, práticas escolares e alternativas de inclusão escolar. Rio de Janeiro: DP\&A Editora, 2003. p. 91-111. 
DIAS SOBRINHO, José. Campo e caminhos da avaliação: a avaliação da educação superior no Brasil. In: FREITAS, Luiz Carlos de (Org.). Avaliação: construindo o campo e a crítica. Florianópolis, SC: Insular, 2002. p. 13-62.

FREITAS, Dirce Nei Teixeira de. A avaliação da educação básica no Brasil: dimensão normativa, pedagógica e educativa. Campinas, SP: Autores Associados, 2007.

GENTIL, Heloísa Salles. Estado e Políticas Públicas: Movimentos Sociais e Resistência. Revista da Faculdade de Educação: política educacional, Cáceres, MT, n. 1, p. 34-55, 2003.

LIMA, Elizeth Gonzaga dos Santos. Avaliação Institucional: o uso dos resultados como estratégia de (re)organização dos espaços de discussão na universidade. 2008. 260 f. Tese (Doutorado em Educação) - Universidade Estadual de Campinas, Campinas, SP, 2008.

PERONI, Vera. Política educacional e papel do Estado no Brasil dos anos 1990. São Paulo: Xamã, 2003.

REZENDE FILHO, Cyro de Barros. A evolução do conceito de cidadania. Revista de Ciências Humanas, Taubaté, SP, v. 7, n. 2, p. 17-23, 2001.

SHIROMA, Eneida; MORAES, Maria Célia Marcondes de; EVANGELISTA, Olinda. Politica Educacional. 4. Ed.. Rio de Janeiro: Lamparina, 2007.

SOUSA, Sandra Zákia. Ensino Médio: Perspectivas de Avaliação. Revista Retratos da Escola, Brasília, DF, v. 5, n. 8, p. 99-110, jan./jun. 2011. 


\section{El ENEM en el contexto de las políticas para la escuela secundaria}

\section{Resumen}

Este artículo tiene como objetivo comprender los determinantes del Exame Nacional do Ensino Médio (ENEM), en Brasil, mediante el análisis de la reforma de las políticas de la Escuela Secundaria y sus interfaces con la evaluación representada por el examen, en el contexto de la promulgación de la ley de Directrices y Bases de Educación Nacional n. 9.394/96 hasta el Nuevo ENEM en 2009. La metodología utilizada se basó en un enfoque cualitativo, y los procedimientos metodológicos fueron análisis de datos, análisis de contenido, sistematizados en tres categorías (evaluación, trabajo y ciudadanía), cuyo estudio empírico fueron los documentos: CEB n o 15/98, la Resolución CNE N o 03/98, el PCNEM base legal, la Ordenanza $\mathrm{N}$ o $438 / 98$ y n ${ }^{\circ} 109 / 2009$. El análisis de los documentos que apoyan la reforma de la Escuela Secundaria mostró que el ENEM es consistente con la política de esta etapa de la educación, ya que sus principios pueden ser identificados tanto en la LDBEN, como en los otros documentos. Los resultados de la investigación también indicó que los principios valorados por las organizaciones multilaterales, en la década de 1990, están presentes en la reforma de la Escuela Secundaria y están directamente relacionados con las políticas neoliberales. Palabras claves: Escuela Secundaria, evaluación, ENEM.

\section{The ENEM in the context of policies for high school}

\section{Abstract}

This article aims to understand the determinants of ENEM, analyzing the policy reform of the high school and its interfaces with the assessment represented by the examination, in the context of the promulgation of law 9.394/96 to the New ENEM in 2009. The methodology used was based on a qualitative approach, with the procedure of data analysis, content analysis, systematized in three categories (assessment, work and citizenship), whose empirical study is made using the following documents: Opinion CEB n o 15/98, CNE Resolution no 03/98, the legal basis PCNEM apart from the ordinance $n^{\circ} 438 / 98$ and $n^{\circ} 109 / 2009$. The analysis of the documents that support the reform of high school showed that ENEM is consistent with the policy for this stage of education, since its principles can be identified both in the law 9.394/96, as discussed in other documents. The survey results also indicated that the principles valued by multilateral organizations, in the 1990s, are present in the reform of high school and it is directly related to neoliberal policies.

Keywords: High school. Evaluation. ENEM. 
Paulo Henrique Alves Machado

E-mail: paulohamachado@hotmail.com

Elizeth Gonzaga dos Santos Lima

E-mail: elizeth@unemat.br

Recebido em: 22/6/2013

Versáo final recebida em: 15/10/2013

Aprovado em: 19/10/2013 